SECTION 21. Pedagogy. Psychology. Innovations in the field of education.

Alpys Abdeshovich Papishev

doctor of pedagogical Sciences, associate Professor of the Department of higher mathematics

L.N.Gumilyov Eurasian National university, Kazakhstan

Darap57@mail.ru

\title{
SOME GLIMPS ABOUT THE STRUCTURE OF MATHEMATICAL ABILITIES, PROCESSES OF THINKING DURING MATHEMATICAL ACTIVITY OF A MAN
}

Abstract: The analysis is provided in article on structure of mathematical abilities and mathematical thinking of the person at his mathematical activity

Key words: psychology, pedagogics, mathematical abilities, mathematical thinking

\section{ПРЕДСТАВЛЕНИЯ О СТРУКТУРЕ МАТЕМАТИЧЕСКИХ СПОСОБНОСТЕЙ, ПРОЦЕССОВ МЫШЛЕНИЯ ПРИ МАТЕМАТИЧЕСКОЙ ДЕЯТЕЛЬНОСТИ ЧЕЛОВЕКА}

\begin{abstract}
Аннотация: B статье приводится анализ по структуре математических способностей и математического мышления человека при его математической деятельности
\end{abstract}

Ключевые слова: психология, педагогика, математические способности, математическое мышление

В связи с научно-технической революцией в нашем обществе возрастает потребность в высококвалифицированных специалистах, связанных с математической деятельностью. Так как основной вклад в развитие той или иной науки делают те её представители, которые проявляют способность в соответствующей области, то учителя математики средней школы должны вести систематическую работу по развитию у школьников математических способностей.

Воспитание необходимых обществу людей могут осуществлять только те учителя, которые сами обладают данными качествами. Это означает, что учитель математики должен обладать качествами, представляющими собой своеобразный синтез педагогических и математических способностей, обеспечивающих успешность преподавания математики в школе.

В психолого-педагогической науке уделяется немалое внимание изучению математических способностей, процессов мышления при математической деятельности человека. Эти исследования связаны с именами Б.Г. Ананьева, В.В. Давыдова, Л.В. Заикова, А.Г. Ковалева, В.Н. Мясищева, В.А. Крутецкого, Н.А. Менчинской и других. Среди зарубежных ученых отметим имена А. Пуанкаре, Э. Торндайка, Ж Пиаже, среди советских ученых-математиков - В.В. Гнеденко, А.Н. Колмогорова, А.И. Маркушевича, А.Я. Хингина, С.И. Шварцбурда и других.

Одним из инициаторов изучения проблемы математических способностей был выдающийся математик А. Пуанкаре. Он выделял три вида математических способностей: арифметические, алгебраические и геометрические, констатировал специфичность творческих математических способностей и указал их важнейший компонент математическую интуицию [1].

Американский психолог Э. Торндайк выделяет общие алгебраические способности: способность обращаться с символами; способность выбора и установления соотношения; способность к обобщению и систематизации; способность приводить в систему идеи и 
навыки. Помимо общих, Э. Торндайк выделяет непосредственно алгебраические способности: понимать и составлять формулы; выражать в виде формулы количественные соотношения; преобразовывать формулы; составлять уравнения, выражающие данные количественные отношения; решать уравнения; выполнять тождественные алгебраические преобразования и т.д. [2].

Среди математиков одним из первых вопросами математических способностей заинтересовался Д. Мордухай-Болиговский. К компонентам математических способностей. К компонентам математических способностей он относил: «сильную память» на математические идеи, мысли факты; «остроумие», позволяющее находить сходное в разнообразных сферах, объединить в одном суждении понятия из малосвязанных областей мысли; быстроту мысли, связанную с тем, что бессознательное мышление протекает быстрее сознательного и помогает ему [3].

Более фундаментальные исследований по проблеме математических способностей математического мышления появились во второй половине XX века. К их числу можно отнести исследования А.Г. Ковалева и В.Н. Мясищева [4], в которых авторы отличают специфичность математического мышления, выделяют «оперные пункты для определения особенности психологических процессов при математической деятельности», а именно: склонность на элементарной ступени развития и операциям с числами, в дальнейшем склонность к решению математических задач, и на ещё более высоком уровне - склонность и интерес к математике; быстрота усвоения счетных и арифметических правил; своеобразная особенность мышления, заключающаяся в том, что развитие абстрактного мышления, аналитико-систематической деятельности, комбинационной способности, особенно сильно сказываются в оперировании цифровой и знаковой символикой; самостоятельность и оригинальность в решении математических проблем, всё более выявляющиеся в процессе овладения математической деятельностью и соотношения репродуктивного и творческого моментов, всё более изменяющиеся в сторону нарастания второго; волевая активность и работоспособность в области математического труда; переход склонности и интереса в увлечение, когда математическая работа становится признанием; продуктивная по количеству и качеству деятельность, позволяющая обнаружить всё более опережающие показатели сверстников [4, с.151]. Всё это интересно, но здесь наблюдается явное отсутствие единой системы. В предлагаемых структурах есть и категория способностей, и умений, и склонностей.

Определенный интерес представляют работы ученых математиков, в которых выделены те или иные аспекты математических способностей.

А.Я. Хингин [5] указал следующие черты математического мышления: доминирование логических схем рассуждений; лаконизм (стремление находить кратчайших путь к цели); четкая расчлененность хода рассуждения; точность (каждый математический символ имеет строго определенное значение).

Академик А.Н. Колмогоров [6] утверждал, что способность к механическому запоминанию большого числа фактов, формул, складыванию или перемножению в уме длинных рядов многозначных чисел не имеют отношения к математическим способностям. В основе последних он выделил: способность умелого преобразования сложных буквенных выражений, нахождение удачных путей для решения уравнений, не подходящих под стандартные правила, или, как это принято называть у математиков, «алгоритмические способности»; геометрическое воображение, или «геометрическая интуиция», искусство последовательного, правильного, правильно-расчлененного логического рассуждения, в частности, хорошим критерием логической зрелости, необходимой математику, является понимание принципа математической дискуссии и умение правильно её применять.

Академик Б.В. Гнеденко в ряде своих публикаций [7,8,9] выделяет следующие свойства математического мышления: способность улавливать нечеткость рассуждения, отсутствие необходимых звеньев доказательства; привычку к полноценной логической 
аргументации; четкую расчлененность хода мысли, рассуждения; лаконизм; точность символики.

С.И. Шварцбурд [10,11] рассматривает следующие компоненты математического мышления: развитие пространственных представлений; умение отличать существенное от несущественного, умение отличать существенное от несущественного, умение абстрагировать, умение от конкретной ситуации перейти к математической формулировке вопроса; навыки дедуктивного мышления; умение анализировать, разбирать частные случаи; умение применять научные выводы на конкретном материале; умение критиковать и ставить новые вопросы; владение достаточно развитой математической речью; обладание достаточным терпением при решении математической задачи.

Приведенные примеры представляют определенный научный интерес, однако и они страдают тем же изъяном: в них нет единой, законченной системы, в них происходит постоянное смешение понятий, умений, навыков, склонностей, способностей.

В.А. Крутецкий обобщая выводы отечественных и зарубежных авторов по данной проблеме, провел достаточно солидные исследования и предложил следующую схему компонентов структуры математических способностей [12].

1. Получение математической информации: способность к формализованному восприятию математического материала, схватывание формальной структуры задачи.

2. Переработка математической информации: способность к логическому мышлению в сфере количественных и пространственных отношений, числовой и знаковой символики, способности мыслить математическими символами, способность к быстрому и широкому обобщению математических объектов, отношений и действий; способность к свертыванию процесса математического рассуждения и системы соответствующих действий; способность мыслить свернутыми структурами, гибкость мыслительных процессов в математической деятельности; стремление к ясности, простоте, экономности и рациональности решений; способность к быстрой и свободной перестройке направленности мыслительного процесса, переключение с прямого на обратный ход мысли (обратимость мыслительного процесса при математическом рассуждении).

3. Хранение математической информации: математическая память (обобщенная память на математические отношения, типовые характеристики, схемы рассуждений и доказательств, методы решения задач и принципы подхода к ним).

4. Общий синтетический компонент: математическая направленность ума. К числу желательных, но не обязательных компонентов В.А. Крутецкий относит:

- быстроту мыслительных процессов как временную характеристику;

- способность к пространственным представлениям;

- способность наглядно представлять абстрактные математические отношения и зависимости.

Итак, мы представили достаточное количество мнений и высказываний ученых по вопросу о структуре математических способностей, чтобы показать, насколько сложна и многогранна эта проблема. В своих исследованиях одни авторы в большей степени касались анализа особенностей психических процессов при математической деятельности, другие обращали внимание на особенности интеллектуальной, эмоционально-волевой сферы человека, занимающегося решением математической проблемы, третьи - свои исследования посвящали перечню умений, необходимых для успешного выполнения математической деятельности. В результате анализа, более чем полутора десятков самостоятельных концепций математических способностей Н.В. Метельским была установлена обобщенная схема компонентов учебно-математических способностей [13] (число показывает частоту повторения компонента):

- сильное абстрагирование, оперирование абстракциями - 15;

- пространственный фактор, геометрическая интуиция - 9;

- четкие логические рассуждения - 8; 
- гибкость, изобретательность мышления - 7;

- математическая интуиция - 6;

- вычислительный, цифровой фактор - 4;

- анализирование, синтез - 3;

- стремление к рациональности решения - 3

- обобщение, нахождение общего в разном - 3 .

Среди способностей к математике по два и одному разу назывались дедуктивное, индуктивное, комбинированное мышление, математическая память и речь, точность символического языка, терпение при решении задачи, умение применять математику, выполнять нестандартные алгебраические преобразования, схематизировать, оперировать свернутыми структурами, склонность и интерес к математике, волевая активность и работоспособность и другие.

К общим интеллектуальным компонентам учебно-математических способностей были отнесены находящие применение в математике (и не только в математике) способности к абстрагированию, обобщению, к генерализированному восприятию ситуации, схемотизированию, к гибкости и логичности мышления, к логическому запоминанию и восприятию, к точности словесного выражения мысли и другие; к специфическим интеллектуальным компонентам - склонность к функциональному мышлению, к пространственному воображению, к строгому доказательству, к решению нестандартных задач, к математическому моделированию, к разработке алгоритмов, к применению алгебраического аппарата и вычислениям, к оперированию математическими абстракциями и символами, к пониманию математических идей, структур и др.

Понятие «математические способности» большинство авторов рассматривают в двух аспектах: как творческие (научные) способности к научной математической деятельности, дающей новые и объективные значимые для человечества результаты; и как учебные способности - способности к изучению (обучению, усвоению) математики, быстрому и успешному овладению соответствующими знаниями, умениями и навыками.

\section{References}

1. Metelsky $\mathrm{N}$ of Century. Psikhologo-pedagogichesky bases of didactics of mathematics. Minsk: Vysheyshy school, 1977. - 160 pages.

2. Torndayk E.L. Arithmetics psychology. / under the editorship of Volkovsky D.L.Per. with English - M.-L. Uchpedgiz, 1932. - 304 pages.

3. Mordukhay-Boltovsky D.Psikhologiya of mathematical thinking//philosophy and psychology Questions. - book 4 - 1908.

4. Kovalev A.T. Myasishchev V. N. Psychological features of the person//Abilities. - L. : Publishing house I LIE, - T.2 - 1960. -304 pages.

5. Hinchin A.Ya. Pedagogical articles. - M: 1963 . - 203 pages.

6. Kolmogorov A.N. About a profession of the mathematician - M: Moscow State University publishing house, - 1959. -31 pages.

7. Gnedenko B. V. Mathematics and mathematical education in the modern world. - M: Education, 1985. - 191 pages.

8. Gnedenko B. V. About mathematical abilities and their development//Mathematics at school. - 1982 . - № 1. - Page 31-34.

9. Gnedenko B. V. Formation of outlook of pupils in the course of training in mathematics. M: Education, 1982. - 145 pages.

10. Shvartsburd S. I. Mathematical specification of pupils of high school. - M: Publishing house of NPA of RSFSR. - 1963 . - 152 pages.

11. Shvartsburd S. I. About development of interests. Tendencies and abilities of pupils to mathematics//Mathematics at school. - 1969 . - № 6. - Page 17-21. 
12. Krutetsky V.A.Psikhologiya of mathematical abilities of school students. - M: Education, 1968. - 431 pages.

13. Metelsky. And. Psychological features of gnostic activity of the teacher: abstract of the thesis of the candidate of pedagogical sciences. - Minsk, 1979. - 19 pages. 